\title{
Safety Climates in Construction Industry: Understanding the Role of Construction Sites and Workgroups
}

\author{
Sílvia Silva ${ }^{1}$, Adriana Araújo ${ }^{2}$, Dário Costa ${ }^{3}$, J. L. Meliá ${ }^{4}$ \\ ${ }^{1}$ ISCTE-IUL Instituto Universitário de Lisboa, Lisbon, Portugal \\ ${ }^{2}$ ISCTE-IUL, Lisboa, Portugal \\ ${ }^{3}$ Organizational and Social Psychology, ISCTE-IUL, Lisboa, Portugal \\ ${ }^{4}$ Department of Methodology, University of Valencia, Valencia, Spain \\ Email: silvia.silva@iscte.pt, adrianareisa@hotmail.com, darioc.costa@hotmail.com, Jose.L.Melia@uv.es
}

Received August 1, 2013; revised September 1, 2013; accepted September 7, 2013

Copyright (C) 2013 Sílvia Silva et al. This is an open access article distributed under the Creative Commons Attribution License, which permits unrestricted use, distribution, and reproduction in any medium, provided the original work is properly cited.

\begin{abstract}
Studies of safety climate in construction revealed a significant positive association between safety climate and various aspects of occupational health and safety. The mechanisms through which this impact operates are still unclear and safety climate is usually studied without considering the complexity of this industry (companies, worksites and groups). The aim of this research is to analyze to what extend there are differences between construction sites and to explore the relations between construction sites' safety climate and workers' safety response and to examine how this influence occur considering the workgroups. The safety climate was evaluated using a reduced version of the questionnaire that is a part of Battery HERC (Herramienta para evaluacion riesgos comportamentales). The data were collected in a Portuguese construction company (5 construction sites; including sub-contractors) comprising 213 workers. Differences between construction sites safety climate were found, suggesting the prevalence of safety sub-climates. The workgroup safety climate played a determinant role on workers' safety response in subcontracted workgroups and it is an important mechanism through which the principal contractor can influence subcontractors' safety response. Designers of prevention and training programs for accidents prevention should include specific contents in order to improve supervisory safety leadership and workgroup safety responses.
\end{abstract}

Keywords: Construction; Safety Climate; Workgroup Safety Climate; Workers’ Safety Response

\section{Introduction}

According to Eurostat, more than one-in-four (26.1\%) fatal accidents at work in the EU-27 in 2009 took place within the construction sector [1]. Work accidents are still a worrying phenomenon, with serious economic and social consequences. In Portugal, construction is one of highest risk industries. Even with recent reductions in incident rates, around $47 \%$ of workplace accidents registered in 2010 occurred in industries $(26.6 \%)$ and construction $(20.6 \%)$. Construction sector leads the total incidence rate, with 91,836 accidents per 100,000 workers, almost twice superior to the overall incidence rate. In 2012, in Portugal, 42 construction workers died [2].

Over the years, research community has tried to identify the factors associated with the accidents occurrence. Studies about safety culture and safety climate in construction focus on organizational and social factors, but safety climate have always been investigated separately at organization and subunit levels. Previous research also emphasizes that sub-climates for safety can exist within an organization. Some research on different groups within organizations has focused on comparing individuals who have not suffered an injury with those who have [3]. Glendon and Litherland [3] applied a modified version of the safety climate questionnaire [4] and found differences in the safety climate of job sub-groups on two of the factors: "Relationships" and "Safety Rules". Gillen and colleagues [5] found statistically significant differences between union and nonunion workers' responses regarding perceived safety climate. Cooper and Phillips [6] found different safety climate perceptions on departments within a company. Despite potential benefits of comparing sub-groups within an organization, few studies have evaluated different groups on a construction site basis. The aim of this research is to analyze to what extend there are differences on safety climate between construction sites 
and to explore the relations between construction sites' safety climate and workers' safety response.

\section{Safety Climate}

\subsection{Background}

Organizational climate refers to shared perceptions among members of an organization with regard to aspects of the organizational environment that inform role behavior, that is, the extent to which certain facets of role behavior are rewarded and supported in any organization [7]. For instance Reichers \& Schneider (1990: p. 22) emphasize the perceptions of organizational policies, practices and procedures, Since organizations have multiple goals and means of attaining goals, senior managers must develop policies and procedures for key organizational facets like customer service, product quality, and employees' safety [8]. Safety climate is a particular area of organizational climate that was introduced in the literature by Zohar [9] and is defined as individual perceptions of the policies, procedures and practices relating to safety in the workplace [10]. A range of factors has been identified as being important components of safety climate: management values (e.g. management concern for employee well-being), management and organizational practices (e.g. adequacy of training, provision of safety equipment, quality of safety management systems), communication and employee involvement in workplace health and safety [11]. The development of shared perceptions about the priority placed upon safety within the work environment is believed to inform workers' role behavior through expectations they form about how certain behaviors will be rewarded and supported in an organization $[7,8]$. During the past few decades, several researchers confirmed the effects of safety climate on employees' safety behaviors [6,11] and on accidents [12-17].

Recently, safety climate has been re-defined as a multilevel construct $[7,13,16,17]$ that emphasized supervisors' safety practices behavior $[13,18,19]$ and co-workers safety practices [16,17]. Meliá and colleagues [20], identified four main safety agents, organization, supervisors, co-workers and worker and five safety climate factors: Organizational safety response, supervisors' safety response, co-workers' safety response, worker's safety response and Perceived risk of accidents. This analysis is relevant because the organizational processes occur simultaneously at different hierarchical levels of an organization; policies and procedures are established at the organization level and are executed at the subunit level (supervisory practices). Policies define strategic goals and the procedures for their attainment, practices are related to the execution of policies by supervisory leaders across the organizational hierarchy [8]. For example, a supervisor who directs workers to disregard certain safety pro- cedures whenever production falls behind schedule creates a distinction between company procedures and subunit practices, thus creating the potential for distinctive sub-climates within one organization.

In addition, the importance of co-workers as a safety climate agent has been reinforced and successfully tested. Recently, results from Brondino and colleagues [17] revealed that co-workers' safety climate had a stronger influence on safety behaviors, and in particular on safety participation, than supervisor's safety climate, at individual level as well at group level.

\subsection{Construction Safety Climate}

The study of the safety climate in construction began with Dedobbeleer and Beland [12] who tested the Brown and Holmes' three-factor safety climate model on construction workers, in nine non-residential construction sites. The results showed that safety was perceived as a joint responsibility of workers and management. Since then, many studies were conducted and revealed a significant positive association between safety climate and various aspects of occupational health and safety performance in the construction industry [5,21-23] and subsequent safety behaviors among Latino residential construction workers, with differences by trade being particularly important [24]. Teo \& Feng [25], in their study about safety culture in construction sites, found that safety climate has an impact on the three dimensions of safety culture, psychological, situational/environmental and behavioral dimensions. According to Meliá and colleagues [20,26], safety climate can be analyzed from the point of view of the agent that performs the safety response in question, by identifying four main safety agents (organization, supervisors, co-workers and worker). In their study, results revealed that organizational safety response and supervisory safety response are strongly related, as are co-worker and worker safety response. In other studies, supervisors' safety response as perceived by workers has been considered a relevant part of safety climate models and therefore it has been included regularly in measures of safety climate, sometimes considering managers and supervisors together [6,27,28]. Lingard \& Blismasa [29] tested a multi-level safety climate model in the Australian construction industry. Subcontracted workers' perceptions of the organizational safety response and supervisor safety response in their own organization and that of the principal contractor were measured using a safety climate survey and the results suggest that supervisors play an important role in shaping safety performance in subcontracted workgroups. The subcontracting is a main characteristic of construction industry and is determinant for the occupational health and safety performance. Subcontractor involvement is a core aspect of construction safety culture 
[30]. Construction subcontractors are often engaged in complex relationships both horizontally (i.e. when multiple subcontractors are engaged by a principal contractor) and vertically (i.e. in the case of pyramid of multilayered subcontracting). In this context, workers involved in subcontracted companies are not connected with the principal contractor and relatively isolated from their own company, which could affect the development and impact of the safety climate [26]. Moreover, considering that workers usually work in groups and have one supervisor it is important to see how much difference the workgroup can make in this specific context. These implications - subcontracting, construction sites and workgroups - and their impact on development of safety climate on the construction industry are still unclear.

The main goal of our research was to analyze the differences on safety climate among construction sites owned by the same principal company and to determine whether workgroup could play a mediation role between safety climate and worker safety response. We formulated the hypothesis as follows:

Hypothesis 1 [H1]: Differences on safety climate exists between construction sites.

Hypothesis 2 [H2]: Construction site safety climate is positive and significantly related with workers' safety response.

Hypothesis 2a [H2a]: The relationship between construction site safety climate and workers' safety response is mediated by workgroup safety climate, centered in supervisors.

Hypothesis $2 \mathrm{~b}[\mathrm{H} 2 \mathrm{~b}]$ : The relationship between construction site safety climate and workers' safety response is mediated by workgroup safety climate, centered in coworkers.

\section{Methodology}

\subsection{Instrument}

For the purpose of this study, the safety climate survey developed by Meliá was used. HERC is an instrument of safety climate that was developed and validated for the construction sector, on the Project "Elaboración y validación de una herramienta diagnostica estandarizada para la evaluación de los riesgos comportamentales y psicosociales ligados a siniestralidad en el sector de la contrucción". The version used comprises 3 parts. The questionnaire contains four scales to construction sites: construction site safety response (e.g. "In the construction site are conducted safety inspections to assess risks"), group safety climate, covering subscales related to co-workers and supervisors' safety responses (e.g. 'My supervisor makes an effort to do his job safely") and workers' safety response (e.g. "When I do my work I follow safety instructions"). The questionnaire has 33 itens and the ques- tions are answered in a six-point Likert scale $(0=$ never, $5=$ continuously).

The questionnaire in this study was applied in one company responsible for five construction sites.

Cronbach's alpha was calculated for each scale to test internal consistency. The construction site safety climate scale revealed an adequate reliability $(\alpha=0.75)$. The group safety response scales and workers' safety response scales also presented good reliability, supervisory $\alpha=0.93$ and co-workers, $\alpha=0.90$ and workers' safety response, $\alpha=0.88$.

\subsection{Participants}

Participants for this study were the construction workers on five construction sites performed by a Portuguese principal construction company. Overall, our sample covers 20 subcontracted companies, $57 \%$ of the total of subcontracted companies, and a total of 213 participants, approximately $65 \%$ of the total number of employees. The majority of the respondents were male $(94.5 \%)$, $20.7 \%$ aged $26-30$.

\section{Results}

Table 1 shows means, standard deviations, and correlations among the variables used in the present study. The means show that respondents perceive high levels of workgroup safety climate, workers' safety response and low levels of construction site safety climate.

All variables are positive and significantly correlated. Construction site safety response and supervisors' safety response $(r=0.51, p<0.01)$ are correlated and construction site safety climate and co-workers' safety response are correlated $(\mathrm{r}=0.39, \mathrm{p}<0.01)$. Supervisors' safety response $(\mathrm{r}=0.63, \mathrm{p}<0.01)$ and co-workers' safety response $(r=0.49, p<0.01)$ have higher correlations with workers' safety response than other variables.

\subsection{Comparison between Construction Sites}

The mean values of the four types of safety responses, obtained in the five construction sites, were compared using an One-Way Anova test. Significant differences between construction sites were found for all the variables ( $F$ values range between 3.35 and 5.96; and $p$ value

Table 1. Descriptive statistics and correlations.

\begin{tabular}{lccccc}
\hline & $\mathrm{M}$ & $\mathrm{SD}$ & 1 & 2 & 3 \\
\hline 1. Construction site safety climate & 2.77 & 0.99 & - & & \\
2. Supervisors' safety response & 3.70 & 1.15 & $0.51^{* *}$ & - & \\
3. Co-workers' safety response & 3.30 & 1.10 & $0.39^{* *}$ & $0.52^{* *}$ & - \\
4. Workers' safety response & 4.03 & 0.88 & $0.27^{* *}$ & $0.63^{* *}$ & $0.49^{* *}$ \\
\hline
\end{tabular}
${ }^{*} \mathrm{p}<0.05 ;{ }^{* *} \mathrm{p}<0.01$. 
between less than 0.001 to 0.01 ).

Table 2 presents the results of the Tukey test (post hoc), to test mean differences between construction sites. As can be seen, in what concerns to construction site safety climate, construction site 1 (CS1) has lower means than all the others constructions sites and construction site 4 (CS4) has higher means. However, we only obtain significant differences between two construction sites (CS2 and CS4).

In what concerns to supervisory safety response, significant differences exists between one and other three construction sites, co-workers safety response presents significant differences between two construction sites and safety response presents significant differences between one and other two construction sites.

With regard to the shared perceptions within construction sites, it was found that only one construction site presented a high degree of consensus, (Rwg range between 0.03 and 0.74 ) which was expected considering the fact that there were employees from different companies.

\subsection{Relation between Safety Climate and Workers' Safety Response and Mediating Role of Workgroup Safety Response}

To test mediation a statistical procedure proposed by Baron and Kenny (1986) was applied and the Sobel test was calculated to check to what extent was or not the mediations significant. The assumptions were verified

Table 2. Variables mean values.

\begin{tabular}{cccccc}
\hline & CS1 & CS2 & CS3 & CS4 & CS5 \\
\hline Construction site safety climate & 1.98 & $2.47 \mathrm{a}$ & 2.29 & $3.02 \mathrm{~b}$ & 2.83 \\
Supervisory safety response & 3.03 & $4.29 \mathrm{a}$ & $3.38 \mathrm{~b}$ & $3.67 \mathrm{~b}$ & $3.68 \mathrm{~b}$ \\
Co-workers safety response & $2.5 \mathrm{a}$ & $3.83 \mathrm{~b}$ & 3.22 & 3.42 & $2.99 \mathrm{a}$ \\
Safety response & 3.6 & $4.45 \mathrm{a}$ & $3.69 \mathrm{~b}$ & $3.91 \mathrm{~b}$ & 4.13 \\
\hline
\end{tabular}

Means with different letters signify that groups are significantly different ( $\mathrm{p}$ $<0.05)$. with correlations analysis.

Regarding the role of workgroup safety climate in the relationship between construction site safety climate and workers' safety response, (Table 3) results revealed that supervisors' safety response, is a complete mediator, since the relation between the predictor variable (construction safety climate) and the outcome variable (workers' safety response) is no longer significant with the introduction of the mediator variable (supervisors' safety response) in the model. Sobel test supports the complete mediation $(\mathrm{z}=6.78, \mathrm{p}<0.01)$. This model explains $37 \%$ of total variance of workers' safety response.

Co-workers' safety response, is also a complete mediator in the relationship between construction site safety climate and workers' safety response (Table 4), since the relation between the predictor variable (construction site safety climate) and the outcome variable (workers' safety response) is no longer significant with the introduction of the mediator variable in the model (co-workers safety response). Sobel test supports that is a complete mediation $(\mathrm{z}=4.76, \mathrm{p}<0.01)$. The model explains $23 \%$ of the total variance of workers' safety response.

To check if the same results would be obtained in the context of specific construction sites, the mediation hypothesis was also tested in the construction sites that had the biggest sample size namely CS2, CS4 and CS5. Overall, a similar mediation results pattern was also found. Namely, it was found a total mediation, supported by Sobel test, from supervisors and co-workers safety response on the relationship between construction site safety climate and workers safety response.

\section{Discussion}

The aim of this research was to analyze to what extend there are differences between construction sites and to explore the relations between construction site safety climate and workers' safety response and to examine how this influence may occur. The present results showed that differences between construction sites exist.

The principal contribution of this study is the inclusion

Table 3. Supervisory safety climate mediation.

\begin{tabular}{cccc}
\hline & \multicolumn{3}{c}{ Criterion variables } \\
\cline { 2 - 4 } & Model 1 & Model 2 & Model 3 \\
\cline { 2 - 4 } & Supervisory safety response & Workers' safety response & Workers' safety response \\
\hline Predictor Variables & $\beta$ & $\beta$ & $\beta$ \\
Construction site safety climate & $0.51^{*}$ & $0.27^{*}$ & -0.07 \\
Supervisory safety response & - & - & $0.65^{*}$ \\
$\mathrm{R}^{2}$ adjusted & 0.26 & 0.06 & 0.37 \\
\hline
\end{tabular}

${ }^{*} \mathrm{p}<0.001$. 
Table 4. Co-workers' safety climate mediation.

\begin{tabular}{cccc}
\hline & \multicolumn{3}{c}{ Criterion variables } \\
\cline { 2 - 4 } & Model 1 & Model 2 & Model 3 \\
\cline { 2 - 4 } & Co-workers safety response & Workers' safety response & Workers' safety response \\
\hline Predictor Variables & $\beta$ & $\beta$ & $\beta$ \\
Construction site safety climate & $0.39^{*}$ & $0.27^{*}$ & 0.10 \\
Co-workers safety response & - & - & $0.44^{*}$ \\
$\mathrm{R}^{2}$ adjusted & 0.15 & 0.06 & 0.23 \\
\hline
\end{tabular}

${ }^{*} \mathrm{p}<0.001$.

of a new agent in construction safety climate analysis - the construction site-which proved to be relevant for the analysis of safety climates. Indeed, construction site is an important, specific and complex part of the construction sector, which is so often referred to in an attempt to explain results in previous studies [20]. Construction subcontractors are often engaged in complex relationships and workers involved in subcontracted companies are not connected with the principal contractor and remain relatively isolated from their own company, which could conduct to sub-units (construction site) safety climate that should be predicted by construction companies.

Concerning to relations between construction site safety climate and workers safety performance, they are positively associated. The mediation role of workgroup, centered on supervisory safety climate and co-workers safety climate, was analyzed. Results shows, as previewed, that supervisory safety climate completely mediates the relationship between construction site safety climate and workers' safety response and that co-workers safety climate also completely mediates the relationship between construction site safety climate and workers' safety response. The results are in agreement with previous findings like the test of psychosocial model of workrelated accidents [16], that shows how safety climate influences workers' safety behavior through supervisors' and coworkers' safety responses and from Lingard, Cooke \& Blismas [29], whose results suggest that supervisors play an important role in shaping safety performance in subcontracted workgroups.

There are some limitations of this study that should be noted. Self-reported data were used, and considering the nature of this context some degree of under-reporting, social desirability, and/or response bias may have occurred. Data were collected using only quantitative techniques. Notwithstanding these limitations, the present research contributes to the organizational safety literature by providing empirical evidence of an agent by which safety climate can be modified and supporting supervisor role in safety promotion.

\section{Conclusions}

This study focuses on the construction sites' specific safety climate that has been understudied. Moreover, previous studies on construction industry's mechanisms upon which safety climate has its impact were still unclear. The present study findings suggest the relevance of construction site safety climates, the prevalence of safety sub-climates and the importance of the workgroup safety climate on workers' safety response in subcontracted workgroups.

Future studies should continue to do deeper analysis that grasps better the nature of construction companies and construction sites. For instance, to analyze sub-contracted companies and it's workgroups operating in one specific construction site. It is important to see if there are differences between contracted companies and in what way the construction safety climate is different from the company safety climate and what ends up to be more determinant of workers' safety behaviors. It will be also important to develop and test adequate intervention programs that can be applied to positively change the safety climate at all the levels as well as the individual's safety response.

Improving safety at work in the construction industry is still a challenge that requires multidisciplinary efforts for developing better prevention interventions.

\section{REFERENCES}

[1] Eurostat, 2012.

http://epp.eurostat.ec.europa.eu/statistics explained/index .php/Health_and_safety_at_work_statistics

[2] ACT, 2013.

http://www.act.gov.pt/(pt-PT)/CentroInformacao/Estatisti $\mathrm{ca} /$ Paginas/default.aspx

[3] A. Glendon and D. Litherland, "Safety Climate Factors, Group Differences and Safety Behavior in Road Construction," Safety Science, Vol. 39, No. 3, 2001, pp. 157188. http://dx.doi.org/10.1016/S0925-7535(01)00006-6

[4] A. I. Glendon, N. A. Stanton and D. Harrison, "Factor Analyzing a Performance Shaping Concepts Question- 
naire," In: S. A. Robertson, Ed., Contemporary Ergonomics, Ergonomics for All, Taylor and Francis, London, 1994, pp. 340-345.

[5] M. Gillen, D. Baltz, M. Gassel, L. Kirsch and D. Vaccaro, "Perceived Safety Climate, Job Demands, and Coworker Support among Union and Nonunion Injured Construction Workers," Journal of Safety Research, Vol. 33, No. 1, 2002, pp. 33-51. http://dx.doi.org/10.1016/S0022-4375(02)00002-6

[6] M. D. Cooper and A. Phillips, "Exploratory Analysis of the Safety Climate and Safety Behavior Relationship," Journal of Safety Research, Vol. 35, No. 5, 2004, pp. 497-512. http://dx.doi.org/10.1016/j.jsr.2004.08.004

[7] D. Zohar and G. Luria, "A Multilevel Model of Safety Climate: Cross-Level Relationships between Organization and Group-Level Climates," Journal of Applied Psychology, Vol. 90, No. 4, 2005, pp. 616-628. http://dx.doi.org/10.1037/0021-9010.90.4.616

[8] D. Zohar, "Safety Climate and beyond: A Multi-Level Multi-Climate Framework," Safety Science, Vol. 46, No. 3, 2008, pp. 376-387. http://dx.doi.org/10.1016/j.ssci.2007.03.006

[9] D. Zohar, "Safety Climate in Industrial Organizations: Theoretical and Applied Implications," Journal of Applied Psychology, Vol. 65, No. 1, 1980, pp. 96-102. http://dx.doi.org/10.1037/0021-9010.65.1.96

[10] A. Neal and M. A. Griffin, "A Study of Lagged Relationships among Safety Climate, Safety Motivation, Safety Behaviour, and Accidents at the Individual and Group Levels," Journal of Applied Psychology, Vol. 91, No. 4, 2006, pp. 946-953. http://dx.doi.org/10.1037/0021-9010.91.4.946

[11] A. Neal, M. A. Griffin and P. M. Hart, "The Impact of Organizational Climate on Safety Climate and Individual Behavior," Safety Science, Vol. 39, 2000, pp. 157-188.

[12] N. Dedobbeleer and F. Beland, "A Safety Climate Measure for Construction Sites," Journal of Safety Research, Vol. 22, No. 2, 1991, pp. 97-103. http://dx.doi.org/10.1016/0022-4375(91)90017-P

[13] D. Zohar, "A Group-Level Model of Safety Climate: Testing the Effect of Group Climate on Micro-Accidents in Manufacturing Jobs," Journal of Applied Psychology, Vol. 85, No. 4, 2000, pp. 587-596. http://dx.doi.org/10.1037/0021-9010.85.4.587

[14] D. Zohar and G. Luria, "Climate as a Social-Cognitive Construction of Supervisory Safety Practices: Scripts as Proxy of Behavior Patterns," Journal of Applied Psychology, Vol. 89, No. 2, 2004, pp. 322-333. http://dx.doi.org/10.1037/0021-9010.89.2.322

[15] S. Silva, M. L. Lima and C. Baptista, "OSCI: An Organizational and Safety Climate Inventory," Safety Science, Vol. 42, No. 3, 2004, pp. 205-220. http://dx.doi.org/10.1016/S0925-7535(03)00043-2

[16] J. L. Meliá, "Un Modelo Causal Psicosocial de los Accidentes Laborales (A Psychosocial Causal Model of Work Related Accidents)," Anuario de Psicología, Vol. 29, No. 3, 1998, pp. 25-43.

[17] M. Brondino, S. Silva and M. Pasini, "Multilevel Ap- proach to Organizational and Group Safety Performance: Co-Workers as the Missing Link," Safety Science, Vol. 50, No. 9, 2012, pp. 1847-1856. http://dx.doi.org/10.1016/j.ssci.2012.04.010

[18] D. Zohar and G. Luria, "The Use of Supervisory Practices as Leverage to Improve Safety Behavior: A Cross-Level Intervention Model," Journal of Safety Research, Vol. 34, No. 5, 2003, pp. 567-577. http://dx.doi.org/10.1016/j.jsr.2003.05.006

[19] J. L. Melià and A. Sesé, "Supervisor's Safety Response: A Multisample Confirmatory Factor Analysis," Psicothe$m a$, Vol. 19, No. 2, 2007, pp. 231-238.

[20] J. L. Meliá, K. Mearns, S. Silva and M. L. Lima, "Safety Climate Responses and the Perceived Risk of Accidents in the Construction Industry," Safety Science, Vol. 46, No. 6, 2008, pp. 949-958. http://dx.doi.org/10.1016/j.ssci.2007.11.004

[21] U. Varonen and M. Mattila, "The Safety Climate and Its Relationship to Safety Practices, Safety of the Work Environment and Occupational Accidents in Eight WoodProcessing Companies," Accident Analysis and Prevention, Vol. 32, No. 6, 2000, pp. 761-769. http://dx.doi.org/10.1016/S0001-4575(99)00129-3

[22] S. Larsson, "Constructing Safety: Influence of Safety Climate and Psychological Climate on Safety Behaviour in Construction Industry," Chalmers University of Technology, Goteborg, 2005.

[23] O. Siu, D. Phillips and T. Leung, "Safety Climate and Safety Performance among Construction Workers in Hong Kong. The Role of Psychological Strains as Mediators," Accident Analysis and Prevention, Vol. 36, No. 3, 2004, pp. 359-366. http://dx.doi.org/10.1016/S0001-4575(03)00016-2

[24] T. A. Arcury, T. Mills, A. J. Marín, P. Summers, S. A. Quandt, J. Rushing, W. Lang and J. G. Grzywacz, "Work Safety Climate and Safety Practices among Immigrant Latino Residential Construction Workers," American Journal of Industrial Medicine, Vol. 55, No. 8, 2012, pp. 736-745. http://dx.doi.org/10.1002/ajim.22058

[25] E. A.-L. Teo and Y. B. Feng, "The Role of Safety Climate in Predicting Safety Culture on Construction Sites," Architectural Science Review, Vol. 52, No. 1, 2009, pp. 5-16. http://dx.doi.org/10.3763/asre.2008.0037

[26] J. L. Meliá, “An Integrative Multilevel Psychosocial view and measurement of Safety Climate," 11th European Congress on Work and Organizational Psychology, Lisbon, 2003.

[27] S. J. Cox and A. J. T. Cheyne, "Assessing Safety Culture in Offshore Environments," Safety Science, Vol. 34, No. 1-3, 2000, pp. 111-129. http://dx.doi.org/10.1016/S0925-7535(00)00009-6

[28] J. L. Melià and M. Becerril, "Safety Climate Dimensions from the 'Agent' Point of View," In: P. Mondelo, M. Mattila, W. Karwowski and A. Hale, Eds., Proceedings of the Fourth International Conference on Occupational Risk Prevention, Seville, 2006.

[29] Helen Clare Lingard, Tracy Cooke and Nick Blismas, "Safety Climate in Conditions of Construction Subcontracting: A Multilevel Analysis," Construction Manage- 
ment and Economics, Vol. 28, No. 8, 2010, pp. 813-825. http://dx.doi.org/10.1080/01446190903480035

[30] S. Mohamed, "Safety Climate in Construction Site Environments," Journal of Construction Engineering and Management, Vol. 128, No. 5, 2000, pp. 375-384.
http://dx.doi.org/10.1061/(ASCE)0733-9364(2002)128:5( $\underline{375)}$ 